\title{
Effect of Post-Heat Treatment on the Microstructure and Mechanical Properties of Laser-Deposited WxC + Ni-Based Composite Thin Walls
}

\author{
Chen Chen, Chengchao Du, Qiuhong Pan, and Qin Chen
}

Submitted: 16 June 2020 / Revised: 16 October 2020 / Accepted: 7 November 2020 / Published online: 24 November 2020

\begin{abstract}
This paper reports the effect of post-heat treatment (PHT) on laser-deposited WxC + Ni-based composite thin walls. The PHT at 700,800 , and $900{ }^{\circ} \mathrm{C}$ was conducted to modify the microstructure and mechanical properties of the composite. The results showed that the as-deposited composite had a weak flexural strength and plasticity due to the brittle nature of the eutectic phase. The eutectic phase consisted of $M_{7} C_{3}$, $\mathrm{M}_{2} \mathrm{C}$, and a small amount of the $\gamma$ phase. However, after PHT at a certain temperature (e.g., 700 or $800{ }^{\circ} \mathrm{C}$ ), the eutectic phase gradually disappeared, and carbides, such as $M_{7} C_{3}$ and $M_{2} C$, tended to be distributed uniformly in the $\gamma$ matrix, which improved the flexural strength of the composite. Nevertheless, after the PHT at $900{ }^{\circ} \mathrm{C}$, the flexural strength of the composite displayed a downward trend, which was mainly because of the severe softening of the $\gamma$ phase. In addition, the plasticity of this composite continuously improved as the eutectic phase disappeared and the $\gamma$ phase softened. Based on the above results, we proposed a $\mathrm{PHT}$ at $800{ }^{\circ} \mathrm{C}$ for $1 \mathrm{~h}$ as an optimal process for this $\mathrm{W} x \mathrm{C}+\mathrm{Ni}$-based composite.
\end{abstract}

Keywords flexural strength, heat treatment, laser deposition, Ni-based composite, plasticity

\section{Introduction}

WC is widely used as a reinforcement in Fe-based alloy (Ref 1), Ni-based alloy (Ref 2, 3), and Co-based alloy (Ref 4, 5). $\mathrm{WC}+\mathrm{Ni}$-based composites generally have the advantages of high hardness, high temperature resistance, and excellent wear resistance and have been widely used in mining machinery (Ref 6-9). Laser deposition is an effective way to fabricated composites. In recent years, composites reinforced by $\mathrm{hBN}$ (Ref 10), SiC (Ref 11), WC (Ref 2), MAX phase (Ref 12), and $\mathrm{WS}_{2}$ (Ref 13) have been fabricated using laser deposition. Among them, the microstructure and mechanical of $\mathrm{WC}+\mathrm{Ni}$ based composites get a lot of attention (Ref 14, 15). It is known that the eutectic phase is a common phase in Ni-based alloys. In Inconel 718 superalloys, the eutectic phase is a mixture of the $\gamma$ phase and Laves phase (Ref 16, 17). In NiCrBSi alloys, the eutectic phase is a mixture of the $\gamma$ phase, carbides, and borides (Ref 18-21). The brittle nature of the Laves phase, carbides, and borides causes the brittle nature of the eutectic phase in Ni-based alloys. These investigations (Ref 22-24) showed that the eutectic phase is an essential factor for cracking formation. To eliminate the adverse effects of the eutectic phase, the microstructure of the eutectic phase should be modified.

Chen Chen, Chengchao Du, and Qiuhong Pan, School of Materials Science and Engineering, Jiangsu University, Zhenjiang 212013, China; and Qin Chen, Zhenjiang Technician Institute, Zhenjiang 212013, China. Contact e-mail: dccmaterials@ujs.edu.cn.
Post-heat treatments (PHTs) are an effective way to modify the morphology of eutectics. Yu et al. (Ref 25, 26) observed the phase transformation of the $\mathrm{Al}_{9}(\mathrm{Mn}, \mathrm{Ni})_{2}$ eutectic phase in an Al-4Ni-2Mn alloy during heat treatment. The results showed that the Al-Ni-Mn $\kappa$-phase preferred to nucleate at the interface between the $\mathrm{Al}$ matrix and the $\mathrm{Al}_{9}(\mathrm{Mn}, \mathrm{Ni})_{2}$ eutectic phase and then grew into the parent phase, which resulted in the breakup of the eutectic fibers at the nucleation sites. Guo et al. (Ref 27) found that the eutectic phase $(\gamma$-phase + Laves $)$ in an Inconel 718 alloy was eliminated by the holding process after deformation. The fraction of the eutectic phase decreased from 5.35 to 2.53 vol. $\%$ after 2 min of holding at $1170{ }^{\circ} \mathrm{C}$. Therefore, a PHT might be an effective way to modify the eutectic phase.

In this investigation, a $\mathrm{WC} / \mathrm{W}_{2} \mathrm{C}(\mathrm{W} x \mathrm{C})$-reinforced Ni-based composite with high hardness and wear resistance was fabricated using laser deposition. A continuous eutectic phase was observed in the Ni-based matrix. To reduce the adverse effects from the eutectic phase, a PHT was employed. Microstructure observations, hardness tests, and three-point bending tests were performed, and the effect of the modified microstructure on the mechanical properties was determined and is discussed.

\section{Materials and Experiments}

The diameter of the Ni-based powder was between $20 \mu \mathrm{m}$ and $50 \mu \mathrm{m}$. The chemical composition of the original Ni-based alloy powder is shown in Table 1 . A cast $\mathrm{W} x \mathrm{C}$ particle with an average diameter of $60 \mu \mathrm{m}$ was employed. The fraction of WC in the $\mathrm{W} x \mathrm{C}$ powder was approximately $44 \mathrm{~mol} . \%$. The two powders (Ni-based powder and $\mathrm{W} x \mathrm{C}$ powder) were mechanically mixed. The volume fraction of $\mathrm{W} x \mathrm{C}$ in the mixture was 30\%. A Trumpf disk 6002 laser generator was employed. A schematic of the laser deposition process is shown in Fig. 1(a). 
Table 1 Chemical composition of original Ni-based alloy powder, wt.\%

\begin{tabular}{lccccc}
\hline & $\mathbf{C r}$ & $\mathbf{W}$ & $\mathbf{S i}$ & $\mathbf{C}$ & $\mathbf{N i}$ \\
\hline Original Ni-based alloy powder & $5.5-6.5$ & $8.5-11.3$ & $2.5-3.0$ & $2.2-2.4$ & Bal \\
\hline
\end{tabular}

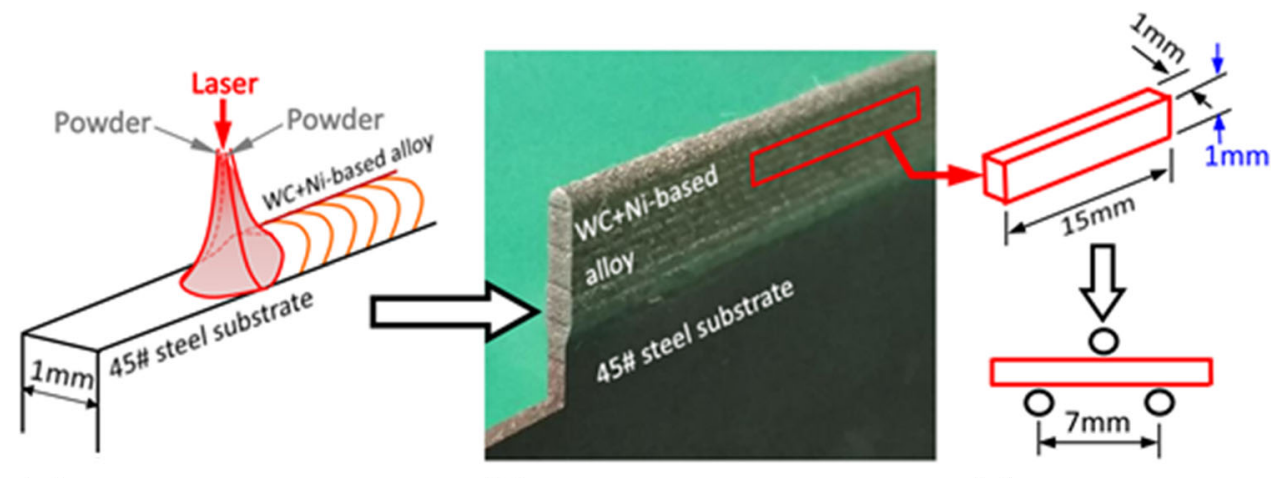

(a)

(b)

(c)

Fig. 1 (a) Schematic of laser depositing process, (b) macro morphology of $\mathrm{W} x \mathrm{C} / \mathrm{Ni}$-based composite, (c) bending sample

The feeding system ejected the mixed powder to the convergent point. The convergent point was just under the laser beam. The powder melted at the convergent point, fell on the substrate, and formed the $\mathrm{W} x \mathrm{C}+\mathrm{Ni}$-based composite. The laser power, feeding speed, and deposition rate were $1.8 \mathrm{~kW}, 8 \mathrm{~g} / \mathrm{min}$, and $15 \mathrm{~mm} / \mathrm{s}$, respectively. The chemical composition of the deposited Ni-based alloy matrix was measured using electron probe microanalysis (EPMA, Shimadzu EPMA-1720) and is shown in Table 1. The macromorphology of the as-deposited $\mathrm{W} x \mathrm{C}+\mathrm{Ni}$-based composite is shown in Fig. 1(b).

The PHT was conducted in a muffle furnace. The PHT temperatures were chosen as 700, 800, and 900. The PHT time was set as $1 \mathrm{~h}$. During the PHT, the samples were placed in a quartz tube filled with Ar gas. After the PHT, the samples were cooled in air. The cross sections of the composites were ground and finally polished using oxide polishing suspensions. Then, the cross sections were etched using aqua regia. The microstructure and fractured surface of the $\mathrm{W} x \mathrm{C}+\mathrm{Ni}$-based composite were observed using scanning electron microscopy (SEM, TESCAN MIRA, FEI NovaNano450). The element distribution of the $\mathrm{W} x \mathrm{C}+\mathrm{Ni}$-based composite was analyzed using EPMA. The composition of the $\mathrm{W} x \mathrm{C}+\mathrm{Ni}$-based composite was analyzed using energy dispersive spectroscopy (EDS, Oxford). The phases of the $\mathrm{W} x \mathrm{C}+\mathrm{Ni}$-based composite were analyzed using x-ray diffraction (XRD, Rigaku Smartlab $9 \mathrm{~kW}$, copper target, $48 \mathrm{kV} / 100 \mathrm{~mA}$ ). Samples with dimensions of $5 \mathrm{~mm} \times 5 \mathrm{~mm} \times 1 \mathrm{~mm}$ were machined from the composites for XRD analysis. The surface with dimensions of $5 \mathrm{~mm} \times 5 \mathrm{~mm}$ was finally ground using 2000-grit sandpaper. The samples were scanned from $20^{\circ}$ to $80^{\circ}$. The scanning speed was $2 \%$ min. The phase transformation diagram was calculated using JMatPro software (Version 6.0). The "Nickel Based Superalloy" database was chosen. A temperature range from 600 to $1500{ }^{\circ} \mathrm{C}$ was set. The chemical compositions of three regions in the Ni-based matrix in the composite were measured using EPMA. The results are shown in Table 2. This result indicated that the average composition of $\mathrm{C}$ reached the maximum value in the original Ni-based composite alloy.
Table 2 Chemical composition of Ni-based matrix of composite and Ni-based alloy for phase diagram calculation, wt. $\%$

\begin{tabular}{llllll}
\hline & Cr & W & Si & C & Ni \\
\hline Region 1 & 5.8 & 11.2 & 2.9 & 2.5 & Bal \\
Region 2 & 5.6 & 10.2 & 2.9 & 2.3 & Bal \\
Region 3 & 6.4 & 9.3 & 2.5 & 2.5 & Bal \\
Average & 5.9 & 10.2 & 2.8 & 2.4 & Bal \\
Ni-based for phase diagram calculation & 6 & 10 & 2.8 & 2.3 & Bal \\
\hline
\end{tabular}

Therefore, considering the error associated with EPMA results, the chemical composition was revised based on the original Nibased alloy powder. The chemical composition for the phase diagram calculation is shown in Table 2. The three-point bending test was conducted with the help of a fixture, as shown in Fig. 1(c). The samples were tested with a loading rate of $0.1 \mathrm{~mm} / \mathrm{min}$ at room temperature and under normal humidity conditions. The flexural strength was calculated according to Eq 1 (Ref 28). The hardness was measured using a microhardness tester (FM-ARS900) with a load of $200 \mathrm{~g}$.

$\sigma=(3 * F * L) /(2 * b * h * h)$

where $F$ is the maximum load, $L$ is the span of the fixture, $b$ is the width of the sample, and $h$ is the thickness of the sample.

\section{Results and Discussion}

\subsection{Results}

3.1.1 Microstructure of the as-Deposited Composite. The cross-sectional macromorphology of the as-deposited $\mathrm{W} x \mathrm{C}+\mathrm{Ni}$-based composite is shown in Fig. 2(a). The microstructure of the region marked in Fig. 2(a) is shown in 

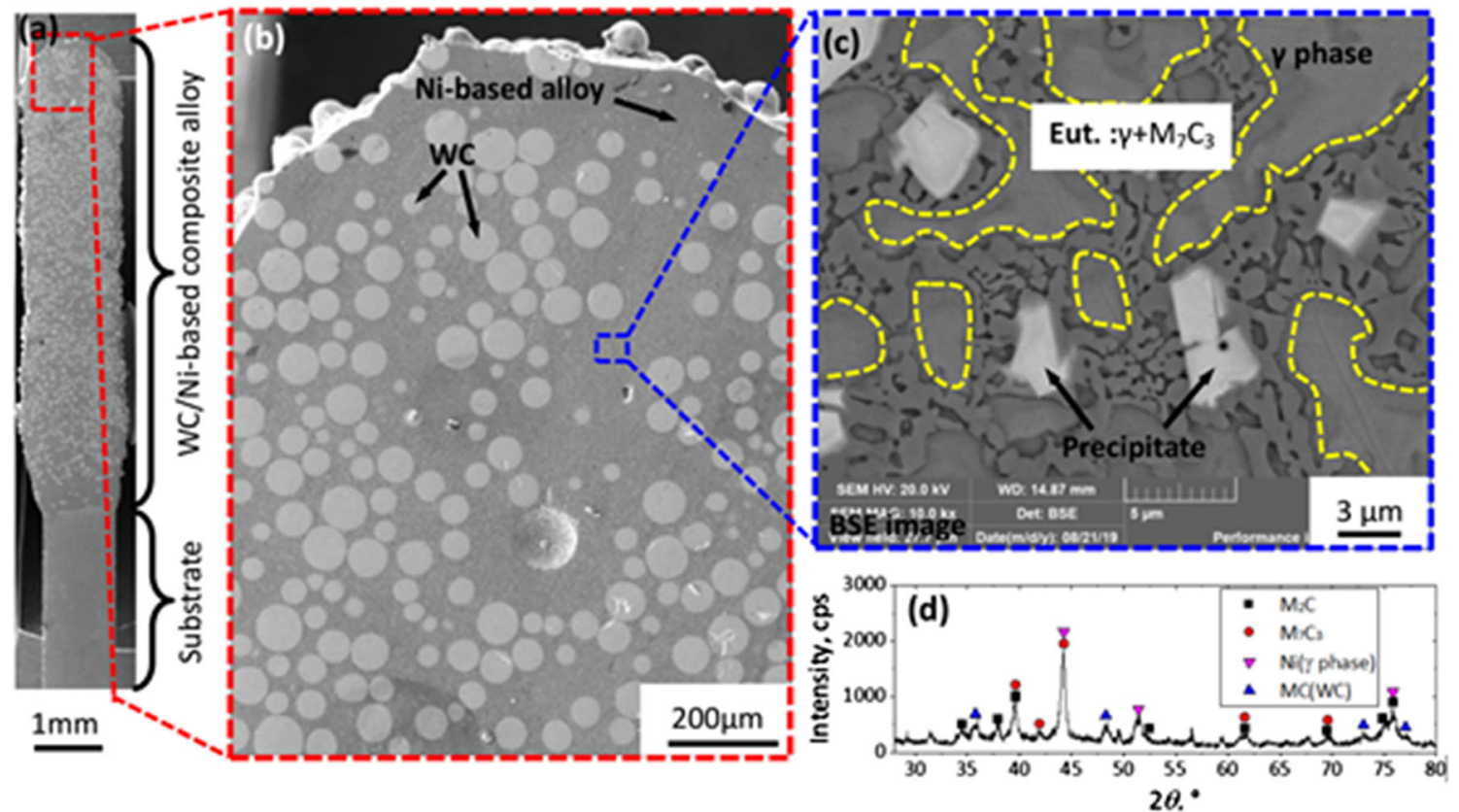

Fig. 2 Microstructure of as-deposited $\mathrm{W} x \mathrm{C}+\mathrm{Ni}$-based composite: (a) macro morphology, (b) micro morphology, (c) Ni-based matrix, (d) XRD pattern

Fig. 2(b). A spherical cast $\mathrm{W} x \mathrm{C}$ particle and the Ni-based alloy matrix are indicated in Fig. 2(b). According to five optical images of the as-deposited composite, the volume fraction of $\mathrm{W} x \mathrm{C}$ was between 25 and $36 \%$. This result indicated that the $\mathrm{W} x \mathrm{C}$ particles were uniformly distributed in the composite. The microscale region of the Ni-based matrix marked in Fig. 2(b) is shown in Fig. 2(c). The microstructure of the Ni-based matrix consisted of the $\gamma$ phase and eutectic phase. The boundary of the two phases is indicated as the yellow line in Fig. 2(c). The $\mathrm{XRD}$ pattern of the as-deposited $\mathrm{W} x \mathrm{C}+\mathrm{Ni}$-based composite is shown in Fig. 2(d). $\mathrm{M}_{2} \mathrm{C}, \mathrm{M}_{7} \mathrm{C}_{3}, \gamma$ phase, and $\mathrm{MC}$ were observed in the as-deposited composite.

The phase transformation diagram of the Ni-based matrix is shown in Fig. 3(a) and (b). The primary $\mathrm{M}_{2} \mathrm{C}$ precipitated from the liquid at $1395{ }^{\circ} \mathrm{C}$, as shown in Fig. 3(a). The primary $\gamma$ phase precipitated at $1269^{\circ} \mathrm{C}$, as shown in Fig. 3(b). When the temperature decreased to $1246{ }^{\circ} \mathrm{C}$, the primary $\gamma$ phase completely precipitated from the liquid. The DSC curve of the Ni-based alloy during heating is shown in Fig. 3(c). At a temperature of approximately $1250{ }^{\circ} \mathrm{C}$, the eutectic phase started to transform into a liquid. Between 1250 and $1281{ }^{\circ} \mathrm{C}$, the primary $\gamma$ phase gradually transformed into a liquid. As there was a low fraction of $\mathrm{M}_{2} \mathrm{C}$, the endothermic dissolution of the $\mathrm{M}_{2} \mathrm{C}$ was not remarkable. According to the DSC curve, the calculated result of the Ni-based matrix was credible.

The eutectic transformation occurred at $1246{ }^{\circ} \mathrm{C}$. The retained liquid directly formed the eutectic phase (secondary $\gamma$ phase and $\mathrm{M}_{7} \mathrm{C}_{3}$ ). At this temperature, $\mathrm{M}_{2} \mathrm{C}$ should rapidly decompose into $\mathrm{M}_{7} \mathrm{C}_{3}$ and $\mathrm{MC}$. However, the primary $\mathrm{M}_{2} \mathrm{C}$ remained until room temperature was reached due to the high cooling speed of the laser deposition process. According to the volume fraction of $\mathrm{M}_{7} \mathrm{C}_{3}$ and primary $\mathrm{M}_{2} \mathrm{C}$, the white precipitate in Fig. 2(c) was $\mathrm{M}_{2} \mathrm{C}$. The eutectic phase consisted of the secondary $\gamma$ phase and $\mathrm{M}_{7} \mathrm{C}_{3}$, as indicated in Fig. 2(c).

The chemical compositions of $\mathrm{M}_{7} \mathrm{C}_{3}$ and $\mathrm{M}_{2} \mathrm{C}$ are shown in Fig. 3(d). The $\mathrm{M}_{7} \mathrm{C}_{3}$ comprised a $\left(\mathrm{Ni}, \mathrm{Cr}\right.$ )-rich phase. The $\mathrm{M}_{2} \mathrm{C}$ comprised a $(\mathrm{Cr}, \mathrm{W})$-rich phase. The element distributions in the region in Fig. 4(a) (as-deposited sample) are shown in Fig. 4(b)-(f). From the distributions of $\mathrm{Ni}$ and $\mathrm{W}$, the white $\mathrm{M}_{2} \mathrm{C}$ phase in the BSE image was confirmed. The EDS patterns from the $\mathrm{M}_{7} \mathrm{C}_{3}$ and $\mathrm{M}_{2} \mathrm{C}$ are shown in Fig. $4(\mathrm{~g})$ and $(\mathrm{h})$. The results from EDS were similar to those from EPMA.

Based on the above results and discussion about the microstructure of the Ni-based matrix, the solidification process of the Ni-based matrix was determined, as shown in Fig. 5. The primary $\mathrm{M}_{2} \mathrm{C}$ gradually precipitated from the liquid between 1395 and $1269{ }^{\circ} \mathrm{C}$, as shown in Fig. 5(a). Between 1269 and $1246{ }^{\circ} \mathrm{C}$, the primary $\gamma$ phase and primary $\mathrm{M}_{2} \mathrm{C}$ precipitated together, as shown in Fig. 5(b) and (c). When the temperature decreased to $1246{ }^{\circ} \mathrm{C}$, the retained liquid phase transformed into the eutectic phase directly, as shown in Fig. 5(d).

3.1.2 Microstructure After the PHT. After the PHT, the eutectic phase gradually disappeared, as shown in Fig. 6(a)-(c). The microstructure consisted of the $\gamma$ phase, $\mathrm{M}_{7} \mathrm{C}_{3}$, and $\mathrm{M}_{2} \mathrm{C}$ after the PHT at temperatures of 700 and $800{ }^{\circ} \mathrm{C}$. After the PHT at $900{ }^{\circ} \mathrm{C}$, a small number of precipitates with a lower contrast was generated, as indicated in Fig. 6(f).

The disappearance of the eutectic phase was common during the PHTs. According to Fig. 2(c), the irregular $\mathrm{M}_{7} \mathrm{C}_{3}$ phase was observed in the eutectic. Many interfaces between the $\mathrm{M}_{7} \mathrm{C}_{3}$ and $\gamma$ phases were observed in the eutectic phase. This contributed to the high interface energy of the as-deposited composite. During the PHTs, the interface energy tended to decrease. Therefore, the irregular $\mathrm{M}_{7} \mathrm{C}_{3}$ changed to reduce the interface energy. In the as-deposited sample, $\mathrm{M}_{7} \mathrm{C}_{3}$ was only in the eutectic phase. The $\mathrm{M}_{7} \mathrm{C}_{3}$ in the composite heat-treated at $900{ }^{\circ} \mathrm{C}$ was uniformly distributed in the $\gamma$ phase matrix. The redistribution of the elements in $\mathrm{M}_{7} \mathrm{C}_{3}$ was element diffusion during the PHT. In the as-deposited composite, $\mathrm{Cr}, \mathrm{W}$, and $\mathrm{C}$ were segregated in the eutectic phase. During PHT, these elements gradually diffused to the primary $\gamma$ phase and contributed to the homogenization of the carbides.

In the as-deposited $\mathrm{W} x \mathrm{C}+\mathrm{Ni}$-based composite, the microstructure at high temperatures was retained to room 


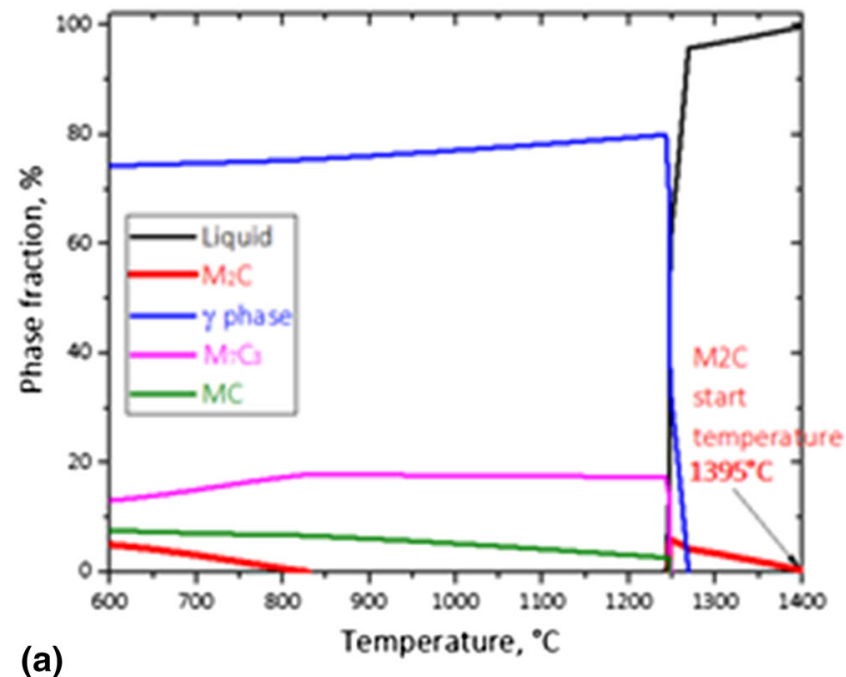

(a)

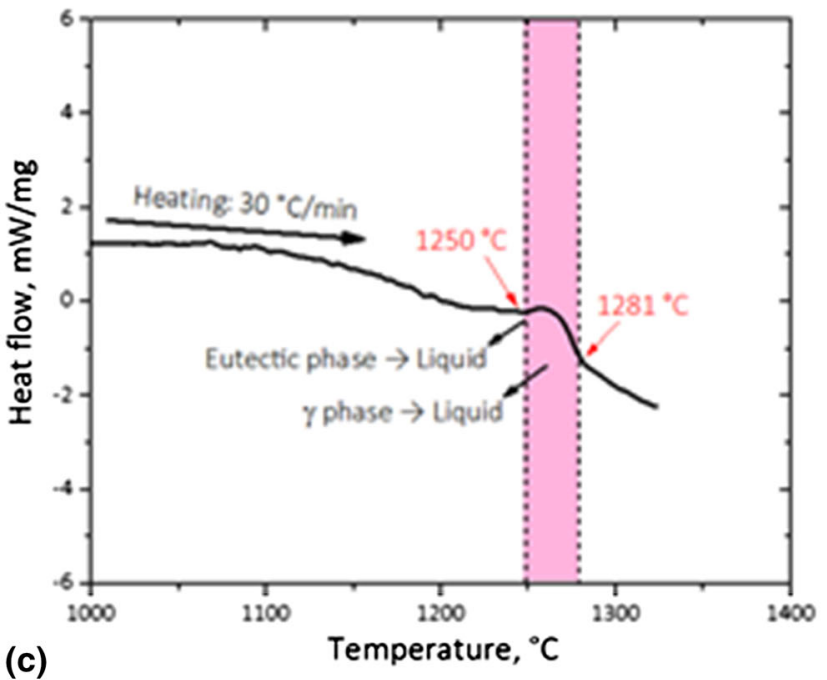

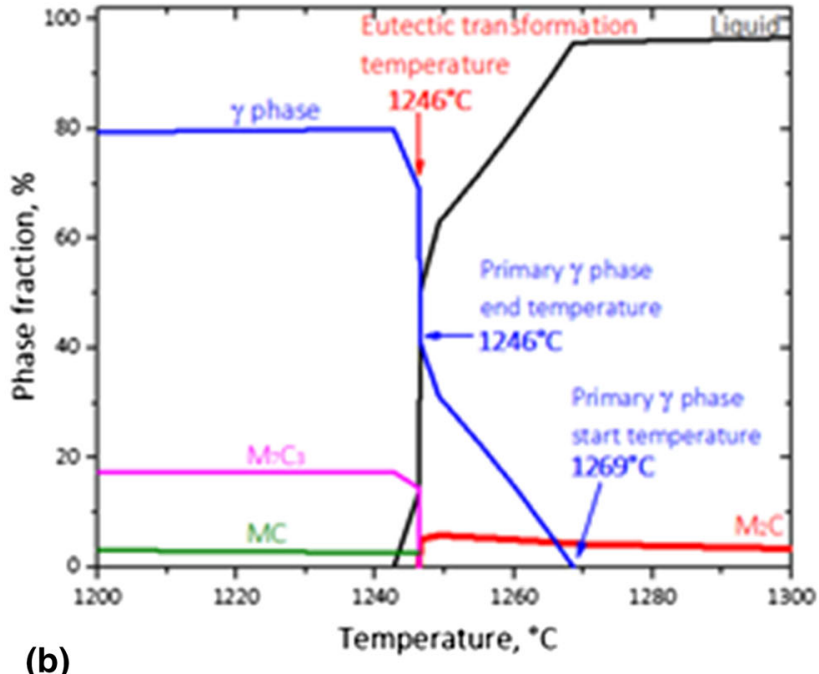

(b)

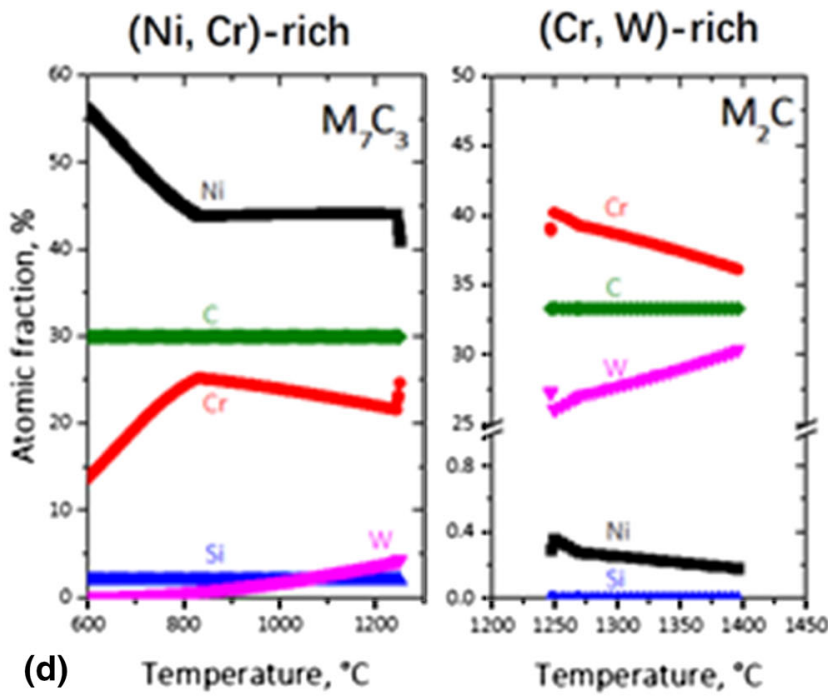

Fig. 3 (a) and (b) Phase diagram of Ni-based matrix, (c) DSC curve of Ni-based matrix, (d) Chemical compositions of $\mathrm{M}_{7} \mathrm{C}_{3}$ and $\mathrm{M}_{2} \mathrm{C}$ as a function of temperature

temperature at a high cooling speed. The phase fractions of $\mathrm{M}_{7} \mathrm{C}_{3}, \mathrm{MC}$, and $\mathrm{M}_{2} \mathrm{C}$ were calculated using JMatPro software and are listed in Table 3. The phase fraction of the Ni-based alloy at $1246{ }^{\circ} \mathrm{C}$ was chosen to represent the microstructure of the as-deposited Ni-based matrix. The phase fraction of $\mathrm{M}_{7} \mathrm{C}_{3}$ was between 15.0 and 18.1 vol.\%. The $\mathrm{M}_{7} \mathrm{C}_{3}$ fraction of the three composites measured from the BSE images was approximately 19 vol.\%. It was concluded that the PHT did not remarkably change the fraction of $\mathrm{M}_{7} \mathrm{C}_{3}$. The phase fraction of $\mathrm{M}_{2} \mathrm{C}$ gradually decreased as the PHT temperature increased.

It was observed that the MC precipitates existed at the three temperatures. Therefore, the MC precipitates were gradually generated during the PHT. The MC precipitates always had a low contrast due to their high carbon fraction. Therefore, they were identified, as shown in Fig. 6(f). According to the difference in contrast in the BSE image, the MC phase was not observed in the composites that underwent PHTs at 700 and $800{ }^{\circ} \mathrm{C}$. The MC phase with a fraction of 3.1 vol. $\%$ was observed in the composite that underwent the PHT at $900{ }^{\circ} \mathrm{C}$.

The reduction in $\mathrm{M}_{2} \mathrm{C}$ and increase in $\mathrm{MC}$ indicated that the $\mathrm{M}_{2} \mathrm{C}$ precipitates were gradually transformed into $\mathrm{MC}$ precip- itates at $900{ }^{\circ} \mathrm{C}$. This phase transformation relied on atomic diffusion. A lower temperature contributed to slower atomic diffusion. The generation of $\mathrm{MC}$ precipitates at temperatures of 700 and $800{ }^{\circ} \mathrm{C}$ was harder than that at $900{ }^{\circ} \mathrm{C}$. Therefore, MC precipitates were not observed in the $\mathrm{W} x \mathrm{C}+\mathrm{Ni}$-based composite heat-treated at temperatures of 700 and $800{ }^{\circ} \mathrm{C}$.

During the PHTs, the microstructure of the $\gamma$ phase also slightly changed. The XRD patterns of the as-deposited and $\mathrm{W} x \mathrm{C}+\mathrm{Ni}$-based composites that underwent a PHT are shown in Fig. 7(a). The angles of the three peaks from the $\gamma$ phase are shown in Fig. 7(b). It was observed that the angles of the three peaks gradually increased and were close to the standard angle for pure Ni. The shift of the peaks was attributed to the solid solution atom diffusion from the $\gamma$ phase to the precipitates.

The atomic fraction of the $\gamma$ phase as a function of temperature was calculated using JMatPro software and is shown in Fig. 7(c). The fractions of $\mathrm{Cr}$, W, and $\mathrm{C}$ gradually declined as the temperature decreased. Regarding the asdeposited alloy, the $\mathrm{Cr}$ fraction was 3.61 at.\%. The $\mathrm{Cr}$ fraction declined to $1.77,1.38$, and 0.96 at.\% at temperatures of 900 , 800 , and $700{ }^{\circ} \mathrm{C}$, respectively. The $\mathrm{Cr}$ fraction of the $\gamma$ phase was measured using EDS, as shown in Fig. 7(d). The lowest $\mathrm{Cr}$ 

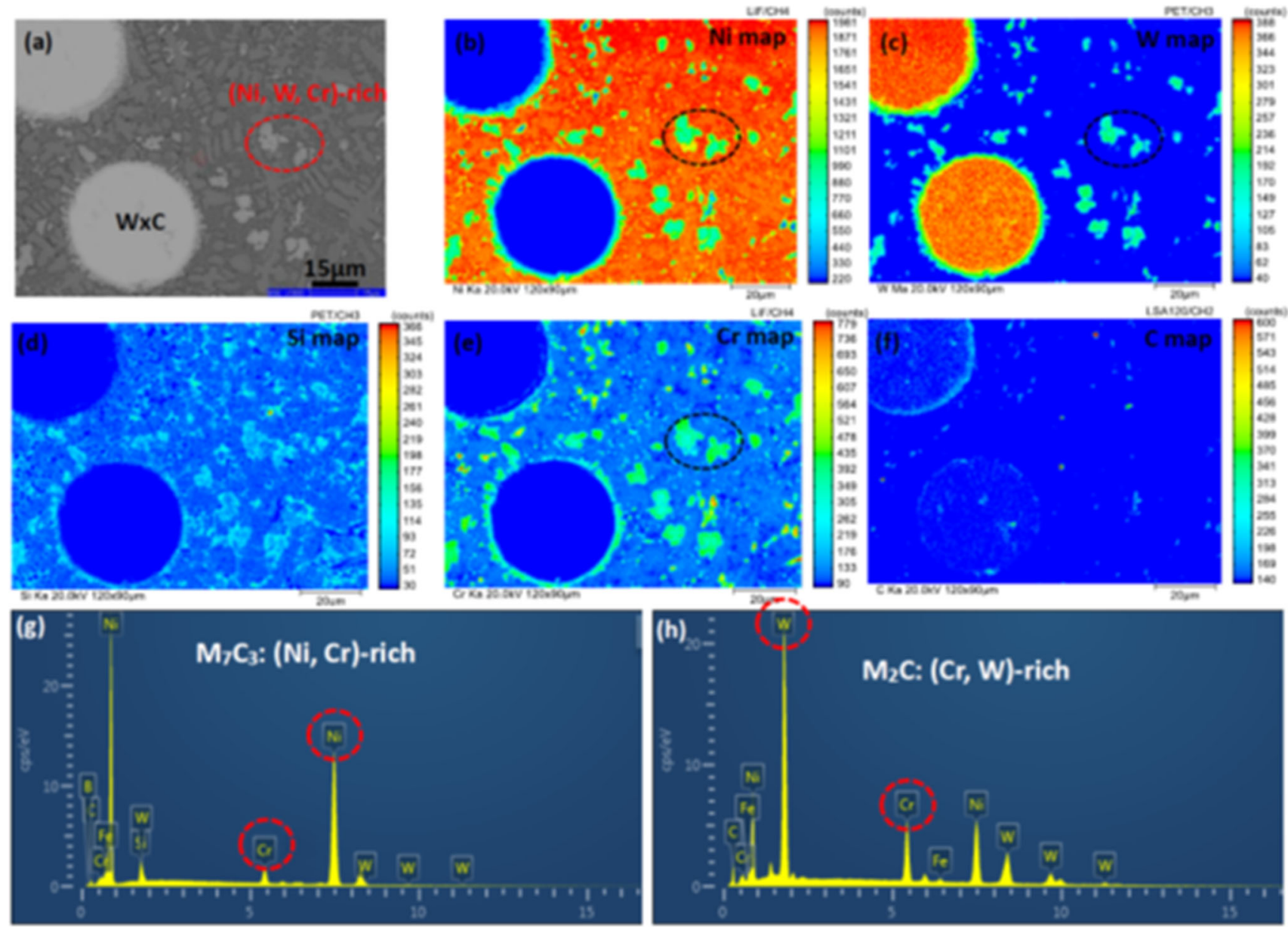

Fig. 4 (a) BSE image of composite, (b) Ni map, (c) W map, (d) Si map, (e) Cr map, (f) C map, (g) EDS pattern of M $\mathrm{C}_{3}$, (h) EDS pattern of $\mathrm{M}_{2} \mathrm{C}$
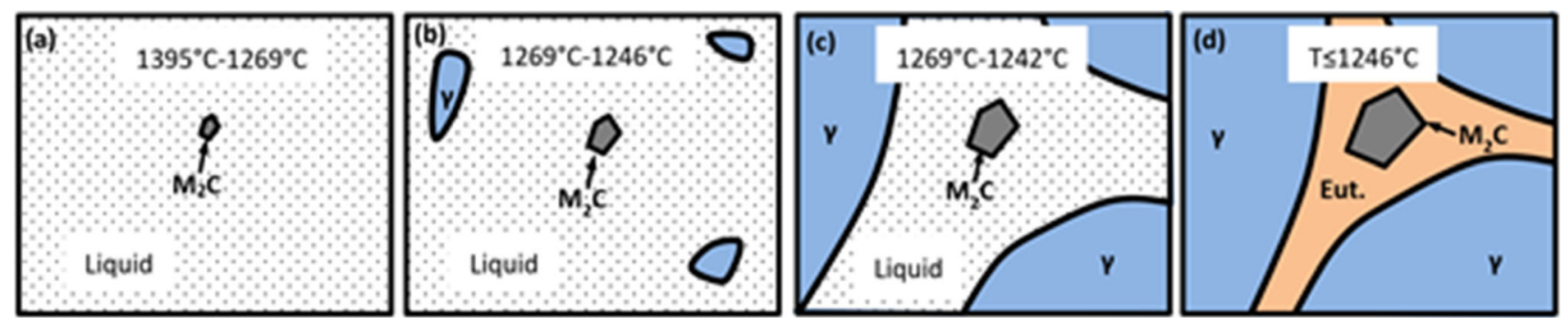

Fig. 5 Solidification procedure: (a) $1395-1269^{\circ} \mathrm{C}$, (b) and (c) $1269-1246{ }^{\circ} \mathrm{C}$, (d) $\leq 1246{ }^{\circ} \mathrm{C}$

fraction of approximately 2.63 at.\% was observed in the $\gamma$ phase after heat treatment at $900{ }^{\circ} \mathrm{C}$.

The reduction in the number of solid solution atoms depended on the diffusion of these atoms during the PHT. The temperature remarkably affected the diffusion rate of these solid solution atoms. The solid solution atoms at $900{ }^{\circ} \mathrm{C}$ had the fastest diffusion among the PHT temperatures. Therefore, the $\gamma$ phase after PHT at $900{ }^{\circ} \mathrm{C}$ had the smallest fraction of solid solution atoms.

3.1.3 Hardness, Flexural Strength, and Plasticity. The hardness of the Ni-based matrix is shown in Fig. 8. It gradually declined from $653 \mathrm{HV}$ to $552 \mathrm{HV}$ as the PHT temperature increased. The hardness of the Ni-based matrix was higher than that of a standard Ni45 alloy (Ref 29). According to the hardness (2124 HV) and volume fraction (30\%) of the $\mathrm{W} x \mathrm{C}$ particles, the hardness of the as-deposited $\mathrm{W} x \mathrm{C}+\mathrm{Ni}$-based composite was approximately $903 \mathrm{HV}$. After a PHT at $900{ }^{\circ} \mathrm{C}$, the hardness of the $\mathrm{W} x \mathrm{C}+\mathrm{Ni}$-based composite declined to approximately $832 \mathrm{HV}$.

The flexural strength and ultimate displacement as a function of PHT temperature are shown in Fig. 9. The sample that underwent $\mathrm{PHT}$ at $800{ }^{\circ} \mathrm{C}$ achieved the maximum flexural strength $(704 \mathrm{MPa})$. The ultimate displacement increased as the PHT temperature increased. This indicated that the composite exhibited excellent flexural strength when heated at $800{ }^{\circ} \mathrm{C}$ for $1 \mathrm{~h}$. The plastic deformation ability of the composite gradually improved as the heating temperature increased. 

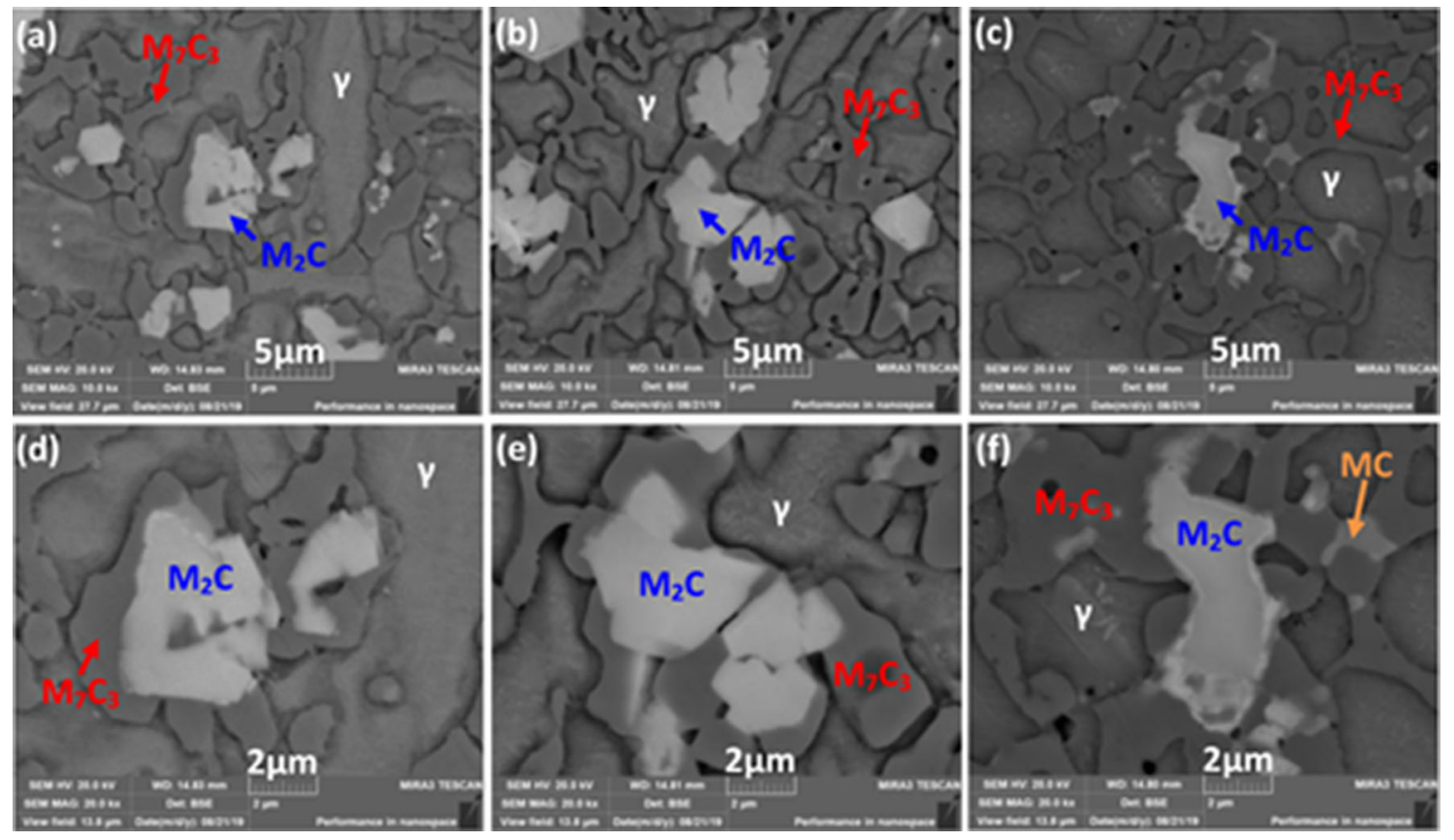

Fig. 6 Microstructure of PHTed Ni-based matrix: (a) and (d) at $700{ }^{\circ} \mathrm{C}$, (b) and (e) at $800{ }^{\circ} \mathrm{C}$, (c) and (f) at $900{ }^{\circ} \mathrm{C}$

Table 3 Phase fraction at 700,800 , and $900{ }^{\circ} \mathrm{C}$, vol.\%

\begin{tabular}{|c|c|c|c|c|c|c|}
\hline \multirow[b]{2}{*}{ Phase } & \multicolumn{2}{|c|}{$\mathbf{M}_{7} \mathbf{C}_{3}$} & \multicolumn{2}{|c|}{$\mathbf{M}_{2} \mathbf{C}$} & \multicolumn{2}{|c|}{ MC } \\
\hline & Calculated & Measured & Calculated & Measured & Calculated & Measured \\
\hline As-deposited at $1246{ }^{\circ} \mathrm{C}$ & 18.1 & $19.4 \pm 1.7$ & 6.3 & $8.8 \pm 2.5$ & 0 & 0 \\
\hline $700^{\circ} \mathrm{C}$ & 15.0 & $19.2 \pm 2.1$ & 3.1 & $8.3 \pm 1.7$ & 7.1 & 0 \\
\hline $800{ }^{\circ} \mathrm{C}$ & 17.0 & $18.7 \pm 1.9$ & 0.6 & $7.9 \pm 0.8$ & 6.7 & 0 \\
\hline $900{ }^{\circ} \mathrm{C}$ & 17.8 & $19.3 \pm 1.6$ & 0 & $6.2 \pm 1.4$ & 6.1 & $3.1 \pm 1.1$ \\
\hline
\end{tabular}

\subsection{Discussion}

3.2.1 Softening Mechanism of the Composite after PHT. The hardness decline of the Ni-based matrix was attributed to the weakening of the strengthening effect. According to Table 3, the total volume fraction of $\mathrm{M}_{7} \mathrm{C}_{3}, \mathrm{M}_{2} \mathrm{C}$, and $\mathrm{MC}$ was approximately 27 vol.\% and was not remarkably changed during PHT. Therefore, the strengthening effect provided by the hard phase was roughly stable during PHT. The composite did not experience plastic deformation. Therefore, the strengthening effect provided by dislocations was also roughly stable during PHT. During the PHT process, the grains should grow. High temperatures contributed to rapid grain growth. The coarse grains contributed to the weakening of the strengthening effect from the grain boundaries (Ref 30, 31). According to the reduction in the solid solution atoms in the $\gamma$ phase, the solid solution strengthening effect of the $\gamma$ phase decreased during PHT (Ref 32). Therefore, the hardness decline of the Ni-based matrix s was attributed to grain growth and a reduction in the number of solid solution atoms in the $\gamma$ phase.

3.2.2 Fracture Behavior of the Composites. The fracture surface of the as-deposited composite is shown in Fig. 10. The SE images are shown in Fig. 10(a) and (c). The BSE images are shown in Fig. 10(b) and (d)-(f). According to Fig. 10(a)-(c), brittle fracture of the WC particles, $\mathrm{M}_{2} \mathrm{C}$, and $\mathrm{M}_{7} \mathrm{C}_{3}$ was observed.
In the as-deposited composite, the $\gamma$ phase was considered the only phase that could undergo plastic deformation. Therefore, the torn edge on the fracture surface was due to plastic deformation of the $\gamma$ phase. Two types of tear edges with different widths were observed in Fig. 10(b) and (e). According to Fig. 10(e) and (f), a narrow tear edge was found between the $\mathrm{M}_{7} \mathrm{C}_{3}$ phase, as shown in Fig. 10(f). In the as-deposited composite, the eutectic phase consisted of $\mathrm{M}_{7} \mathrm{C}_{3}$ and the secondary $\gamma$ phase. The fine secondary $\gamma$ phase was between the continuous $\mathrm{M}_{7} \mathrm{C}_{3}$ precipitates. Therefore, the plastic deformation of the secondary $\gamma$ phase in the eutectic phase contributed to the narrow tear edge in Fig. 10(e).

In Fig. 10(b) and 11(a), a wide tear edge is indicated. The formation of a wide tear edge was dependent on the plastic deformation of the coarse $\gamma$ phase. The primary $\gamma$ phase in the as-deposited composite is shown in Fig. 11(b). A coarsened $\gamma$ phase surrounded by the eutectic phase was observed. During the bending test, the plastic deformation of the primary $\gamma$ phase contributed to the formation of a wide tear edge.

Based on the above discussion, the fracture of the asdeposited composite depended on two factors: (a) brittle fracture of $\mathrm{WC}, \mathrm{M}_{2} \mathrm{C}$, and $\mathrm{M}_{7} \mathrm{C}_{3}$; and (b) ductile fracture of the primary $\gamma$ phase and secondary $\gamma$ phase. In the as-deposited composite, the plastic deformation ability of the $\gamma$ phase was limited due to the increased solid solution strengthening effect. 

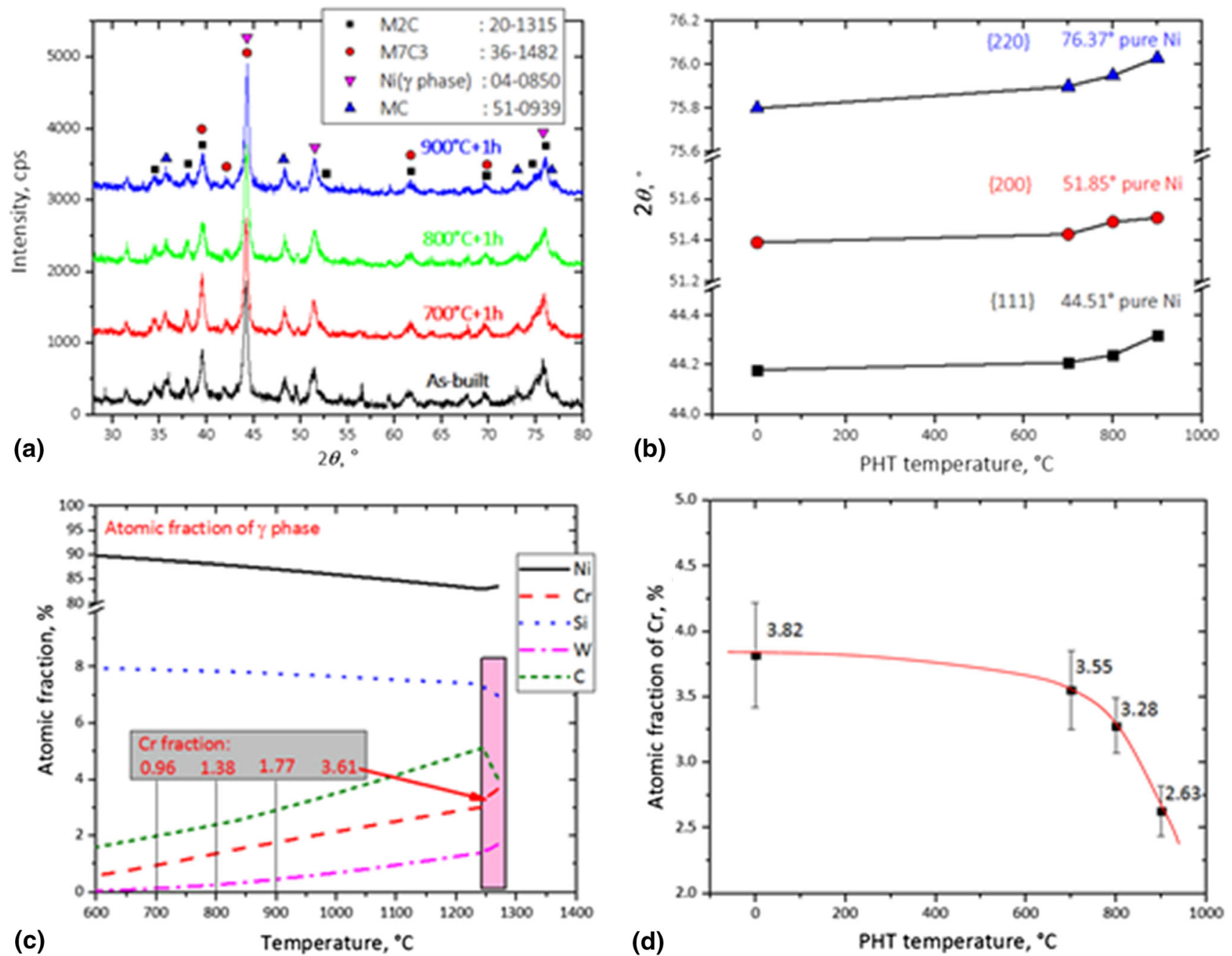

Fig. 7 (a) XRD patterns, (b) Angle of three peaks of $\gamma$ phase, (c) Composition of $\gamma$ phase as a function of temperature, (d) Atomic fraction of $\mathrm{Cr}$ as a function of PHT temperature

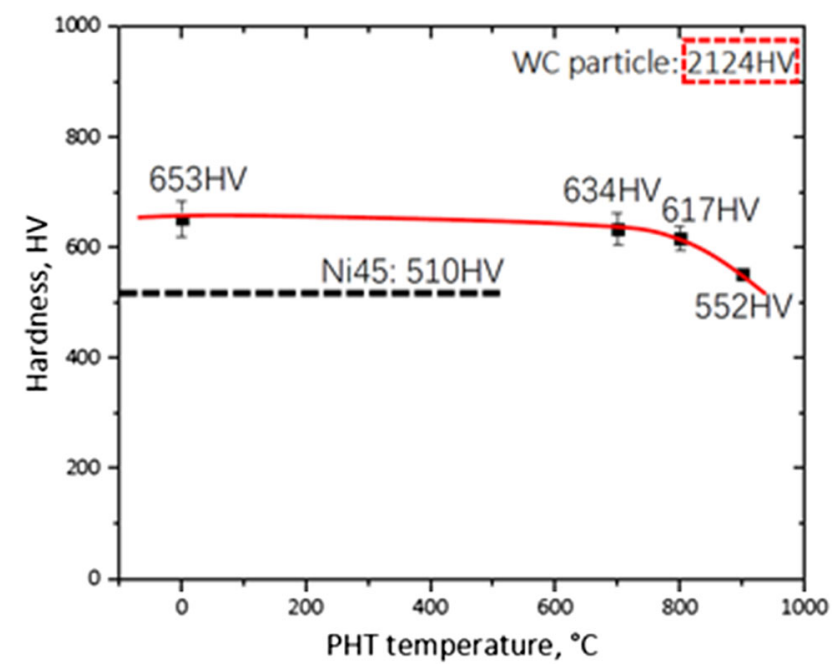

Fig. 8 Hardness of Ni-based matrix as a function of PHT temperature

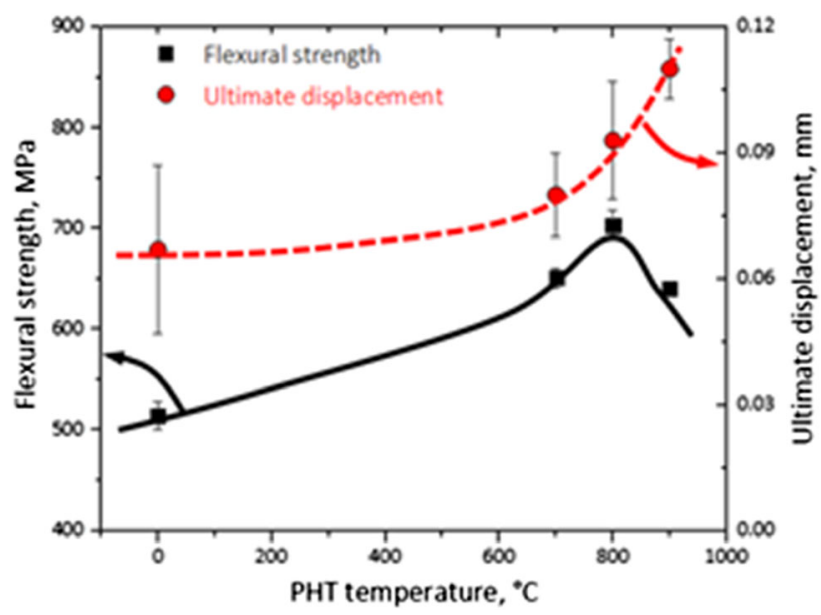

Fig. 9 Flexural strength and ultimate displacement as a function of PHT temperature 

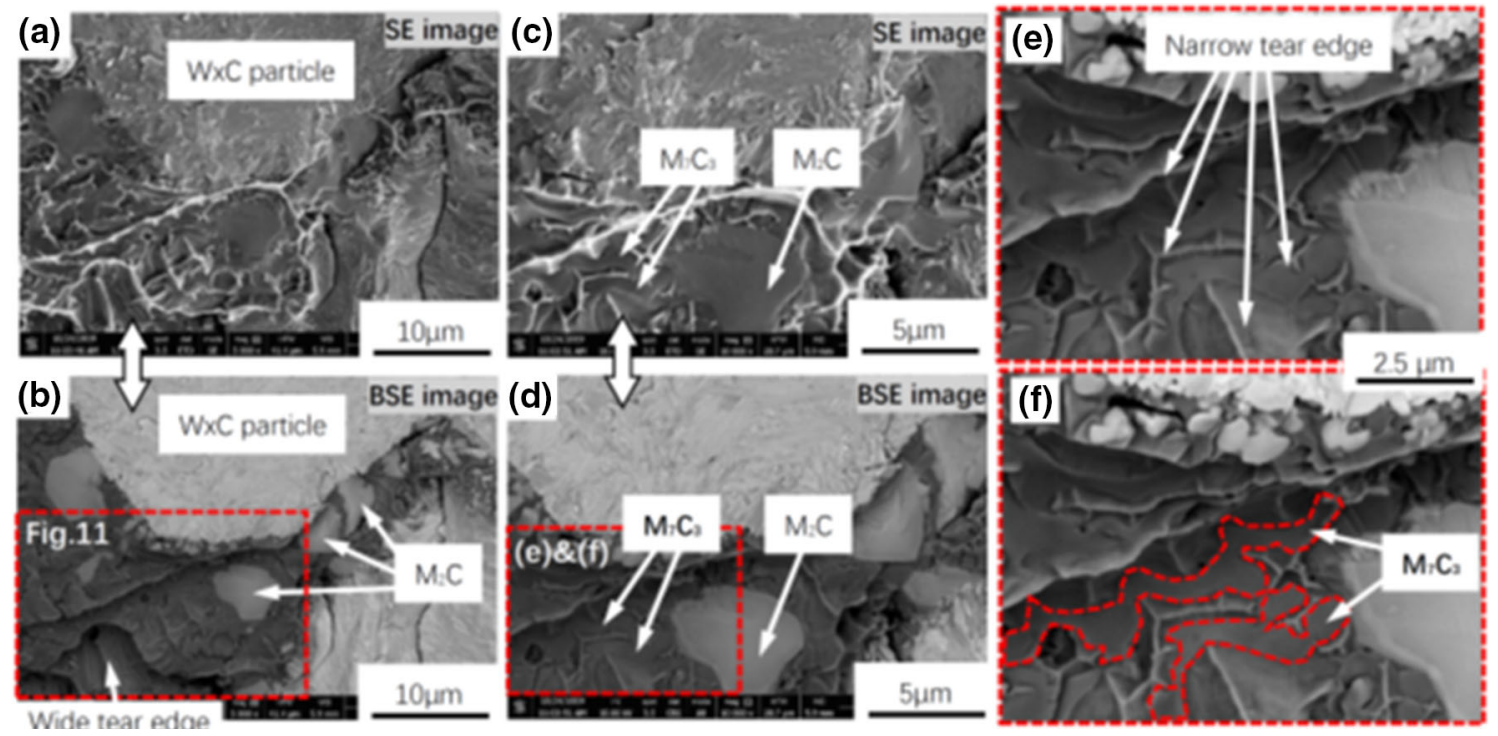

Fig. 10 Fracture surfaces of as-deposited $\mathrm{W} x \mathrm{C}+$ Ni-based composite: (a) and (c) SE images; (b), (d), (e), and (f) BSE images
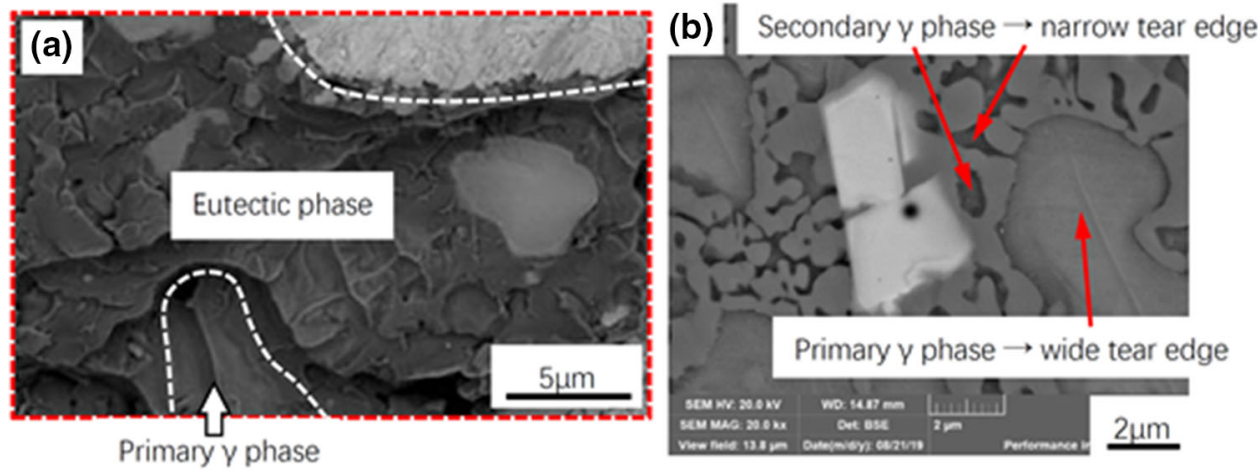

Fig. 11 (a) Fracture surface as indicated in Fig. 10, (b) microstructure of as-deposited composite

Therefore, dimples were not observed on the fracture surface. The eutectic phase induced crack propagation due to its high fraction of $\mathrm{M}_{7} \mathrm{C}_{3}$ and $\mathrm{M}_{2} \mathrm{C}$.

The fracture surfaces of the composite PHT at $700{ }^{\circ} \mathrm{C}$ are shown in Fig. 12(a) and (b). A similar result to the that for the as-deposited composite was observed for the fracture surfaces. After PHT at $800{ }^{\circ} \mathrm{C}$, the brittle fracture of $\mathrm{WxC}, \mathrm{M}_{2} \mathrm{C}$, and $\mathrm{M}_{7} \mathrm{C}_{3}$ was still observed in Fig. 12(c) and (d). The continuous fracture of $\mathrm{M}_{7} \mathrm{C}_{3}$ was not observed on the fracture surface. According to Fig. 6(b) and (e), the continuous $\mathrm{M}_{7} \mathrm{C}_{3}$ in the asdeposited composite was modified. The coarsened $\gamma$ phase between the $\mathrm{M}_{7} \mathrm{C}_{3}$ precipitates was observed. Therefore, the continuous fracture of $\mathrm{M}_{7} \mathrm{C}_{3}$ was restricted.

The wide tear edge is indicated in Fig. 12(c) showed ductile fracture of the coarse $\gamma$ phase. Moreover, dimples were observed on the fracture surface, as shown in Fig. 12(e). This meant that the plastic deformation ability of the $\gamma$ phase in the composite that underwent PHT at $800{ }^{\circ} \mathrm{C}$ was enhanced.

The fracture surfaces of the composite that underwent PHT at $900{ }^{\circ} \mathrm{C}$ are shown in Fig. 13. According to the SE images [Fig. 13(a) and (c)] and BSE images [Fig. 13(b) and (d)], brittle fracture of $\mathrm{W} x \mathrm{C}, \mathrm{M}_{2} \mathrm{C}$, and $\mathrm{M}_{7} \mathrm{C}_{3}$ was observed. According to Fig. 13(e), a remarkable dimpling was observed. In the composite that underwent $\mathrm{PHT}$ at $900{ }^{\circ} \mathrm{C}$, the coarse $\gamma$ phase was surrounded by $\mathrm{M}_{7} \mathrm{C}_{3}$, as shown in Fig. 6(c). During the bending test, the coarsened $\gamma$ phase experienced severe plastic deformation and contributed to the formation of dimples. The formation of dimples also indicated an improved plastic deformation ability of the $\gamma$ phase in the composite that underwent PHT at $900{ }^{\circ} \mathrm{C}$.

Based on the above discussion, the fracture of the composite that underwent PHT at $900{ }^{\circ} \mathrm{C}$ depended on two factors: (a) brittle fracture of $\mathrm{WC}, \mathrm{M}_{2} \mathrm{C}$, and $\mathrm{M}_{7} \mathrm{C}_{3}$; and (b) ductile fracture of the $\gamma$ phase. In the composite that underwent PHT, the plastic deformation ability of the $\gamma$ phase was enhanced as the solid solution strengthening effect weakened. Therefore, dimples were observed on the fracture surface. The eutectic phase disappeared and no longer induced crack propagation.

3.2.3 Enhancing Mechanism of Bending Properties. A higher hardness always contributes to a higher strength. However, the highest hardness of the as-deposited composite did not contribute the highest flexural strength in this investigation. This was attributed to the continuous eutectic phase. The eutectic phase, which has a high fraction of brittle $\mathrm{M}_{7} \mathrm{C}_{3}$ and $\mathrm{M}_{2} \mathrm{C}$, contributed to crack initiation and propagation during the bending test. After PHT at 700 and $800{ }^{\circ} \mathrm{C}$, the continuous 


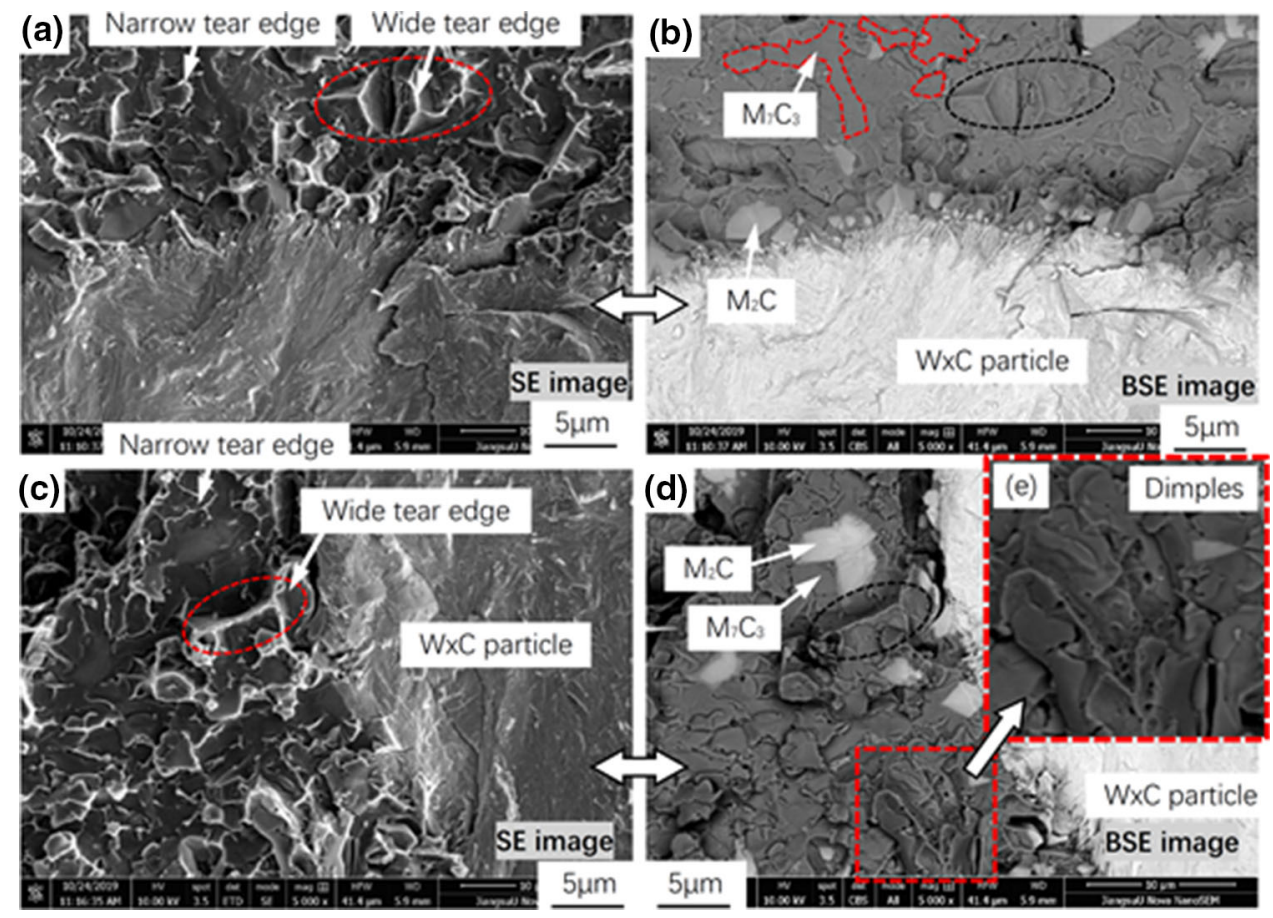

Fig. 12 (a) and (b) Fracture surfaces of composite heat-treated at $700{ }^{\circ} \mathrm{C}$, (c)-(e) Fracture surfaces of composite heat-treated at $800{ }^{\circ} \mathrm{C}$
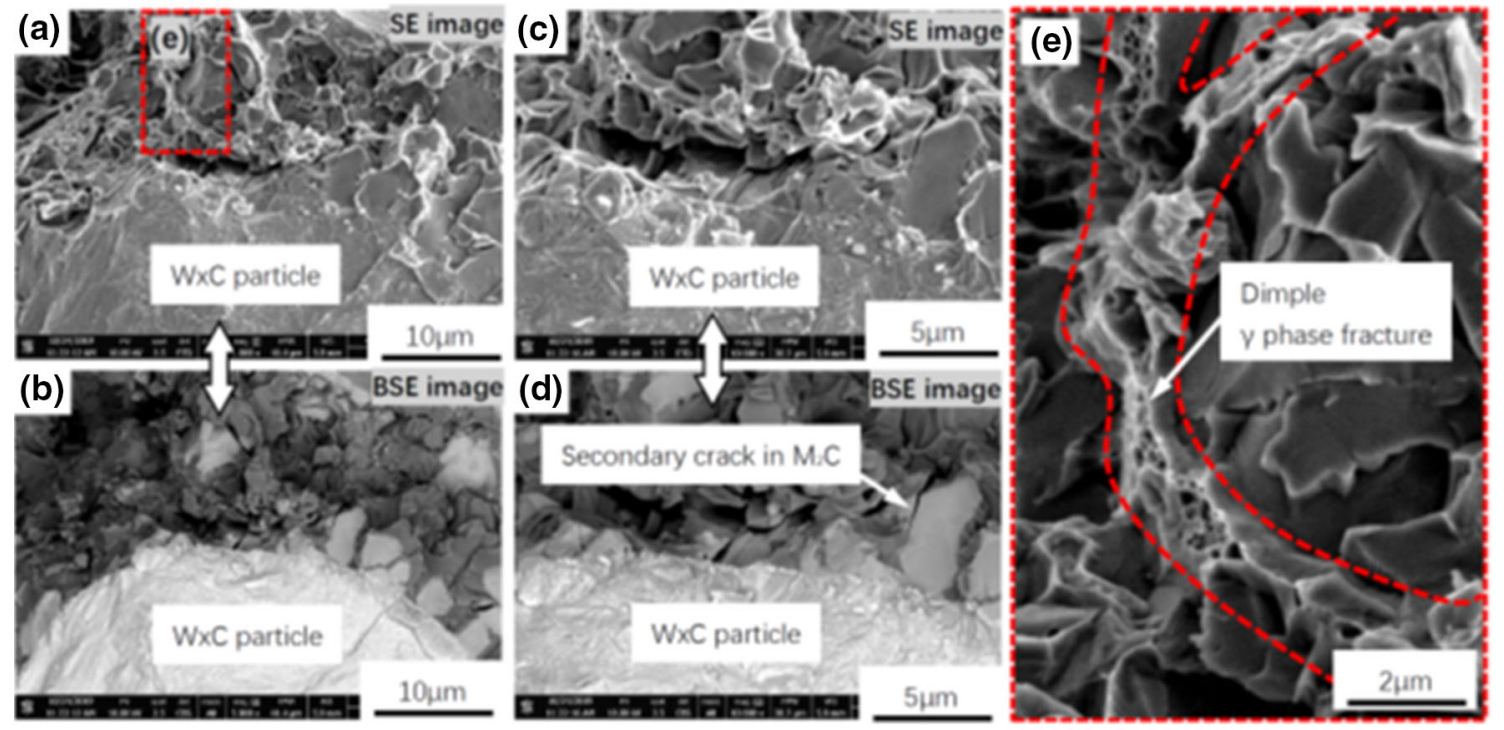

Fig. 13 Fracture surfaces of composite heat-treated at $900{ }^{\circ} \mathrm{C}$ : (a) and (c) SE images; (b), (d), and (e) BSE images

eutectic phase gradually disappeared. Therefore, the flexural strength increased to $704 \mathrm{MPa}\left(800{ }^{\circ} \mathrm{C}\right)$ from $515 \mathrm{MPa}$ (asdeposited composite). When PHT at $900{ }^{\circ} \mathrm{C}$, remarkable softening of the $\gamma$ phase occurred. The hardness of the Nibased matrix declined to $552 \mathrm{HV}$. The poor strengthening of the $\gamma$ phase contributed to the decrease in the flexural strength compared with that for the composite that underwent PHT at $800{ }^{\circ} \mathrm{C}$.

The ultimate displacement depended on the plastic deformation ability of the composite. Regarding the as-deposited composite, the cracking of the eutectic phase limited the plastic deformation. After PHT, the eutectic phase gradually disappeared. The ultimate displacement improved. Moreover, the softening of the $\gamma$ phase also contributed to the plastic deformation ability of the composite after PHT. The gradually enhanced plastic deformation ability of the $\gamma$ phase contributed to the transformation from the formation of tear edges to dimples on the fracture surfaces.

\section{Conclusions}

1. The thermodynamic calculations based on JMatPro software indicated that during the cooling stage of the $\mathrm{W} x \mathrm{C}+\mathrm{Ni}$-based composite, $\mathrm{M}_{2} \mathrm{C}$ precipitated from the 
liquid at $1395{ }^{\circ} \mathrm{C}$. The primary $\gamma$ phase started precipitating at $1269^{\circ} \mathrm{C}$. When the temperature declined to $1246{ }^{\circ} \mathrm{C}$, the primary $\gamma$ phase completely precipitated from the liquid with a volume fraction of $41 \%$. The residual liquid rapidly transformed into the eutectic phase. The primary $\mathrm{M}_{2} \mathrm{C}$ in the eutectic phase was retained at room temperature at a high cooling speed.

2. After the PHT process, the eutectic phase gradually disappeared. $\mathrm{M}_{7} \mathrm{C}_{3}$ and $\mathrm{M}_{2} \mathrm{C}$ were gradually uniformly distributed in the Ni-based matrix. After PHT at $900{ }^{\circ} \mathrm{C}$, a small amount of $\mathrm{MC}$ was generated. The reduction in the number of solid solution atoms in the $\gamma$ phase was increased progressively as the PHT temperature increased.

3. The hardness of the Ni-based matrix gradually declined as the PHT temperature increased. This trend was due to coarsening of the grains and a reduction in the number of solid solution atoms in the $\gamma$ phase.

4. The flexural strength of the samples heat-treated at 700 and $800{ }^{\circ} \mathrm{C}$ continuously increased as the eutectic phase disappeared. The decline in the flexural strength of the sample that underwent $\mathrm{PHT}$ at $900{ }^{\circ} \mathrm{C}$ was attributed to the substantial softening of the Ni-based matrix.

5. The bending displacement of the samples continuously increased as the PHT temperature increased. The disappearance of the eutectic phase and softening of the $\gamma$ phase contributed to the improvement in the plastic deformation ability of the Ni-based matrix together.

\section{Acknowledgments}

The authors would like to express their gratitude for projects supported by the National Key R\&D Program of China (Grant No. 2019YFC0810704). In addition, all authors are particularly grateful to the medical staff who have fight against the COVID-19 for providing us with a safe research environment.

\section{References}

1. J.Z. Lu, J. Cai, H.F. Lu et al., Wear Properties and Microstructural Analyses of Fe-Based Coatings with Various WC Contents on H13 Die Steel by Laser Cladding, Surf. Coat. Technol., 2019, 369, p 228-237

2. R. Zhou, G.F. Sun, A.X. Feng et al., Effects of Yttrium on the Microstructure and Wear Properties of Laser-Aided Direct Metal Deposition (DMD) Co-285 + WC Coatings, Lasers Eng., 2015, 31, p 161-178

3. S. Hong, Y. Wu, J. Wu et al., Effect offlow Velocity on Cavitation Erosion Behavior of HVOF Sprayed WC-10Ni and WC-20Cr3C2-7Ni Coatings, Int. J. Refract. Met. Hard Mater., 2020, 92, p 105330

4. G.F. Sun, K. Wang, R. Zhou et al., Effect of Annealing on Microstructure and Mechanical Properties of Laser Deposited Co285 + WC Coatings, Opt. Laser Technol., 2015, 66, p 98-105

5. D. Shu, Z. Li, K. Zhang et al., In Situ Synthesized High Volume Fraction WC Reinforced Ni-Based Coating by Laser Cladding, Mater. Lett., 2017, 195, p 178-181

6. E.O. Correa, J.N. Santos, and A.N. Klein, Microstructure and Mechanical Properties of WC Ni-Si Based Cemented Carbides Developed by Powder Metallurgy, Int. J. Refract. Met. Hard Mater., 2010, 28, p 572-575

7. E. Hao, X. Zhao, Y. An et al., WC-Co Reinforced NiCoCrAlYTa Composite Coating: Effect of the Proportion on Microstructure and Tribological Properties, Int. J. Refract. Met. Hard Mater, 2019, 84, p 104978

8. M. Zhang, M. Li, J. Chi et al., Effect of Ti on Microstructure Characteristics, Carbide Precipitation Mechanism and Tribological
Behavior of Different WC Types Reinforced Nibased Gradient Coating, Surf. Coat. Technol., 2019, 374, p 645-655

9. J. Škamat, O. Černašejus, Ž. Čepukè et al., Pulsed Laser Processed $\mathrm{NiCrFeCSiB} /$ WC Coating Versus Coatings Obtained Upon Applying the Conventional Re-melting Techniques: Evaluation of the Microstructure, Hardness and Wear Properties, Surf. Coat. Technol., 2019, 374, p 1091-1099

10. X.L. Lu, X.B. Liu, P.C. Yu et al., Synthesis and Characterization of Ni60-hBN High Temperature Self-lubricating Anti-wear Composite Coatings on Ti6Al4V Alloy by Laser Cladding, Opt. Laser Technol., 2016, 78, p 87-94

11. Z. Wu, F. Zhou, K. Chen et al., Friction and Wear Properties of CrSiCN Coatings with Low Carbon Content as Sliding Against SiC and Steel Balls in Water, Tribol. Int., 2016, 94, p 176-186

12. Q. Shi, H. Zhu, and C. Li, The Effects of the Addition of Ti3SiC2 on the Microstructure and Properties of Laser Cladding Composite Coatings, Coatings, 2020, https://doi.org/10.3390/coatings 10050498

13. W. Chen, B. Liu, L. Chen et al., Effect of Laser Cladding Stellite 6Cr3C2-WS2 Self-Lubricating Composite Coating on Wear Resistance and Microstructure of H13, Metals, 2020, https://doi.org/10.3390/me t10060785

14. M. Xia, D. Gu, C. Ma et al., Fragmentation and Refinement Behavior and Underlying Thermodynamic Mechanism of WC Reinforcement During Selective Laser Melting of Ni-Based Composites, J. Alloys Compd., 2019, 777, p 693-702

15. Q.B. Nguyen, Z. Zhu, B.W. Chua et al., Development of WC-Inconel Composites Using Selective Laser Melting, Arch. Civ. Mech. Eng., 2018, 18, p 1410-1420

16. K. Wang, Y. Liu, Z. Sun et al., Microstructural Evolution and Mechanical Properties of Inconel 718 Superalloy Thin Wall Fabricated by Pulsed Plasma Arc Additive Manufacturing, J. Alloys Compd., 2020, 819, p 152936

17. M.J. Sohrabi, H. Mirzadeh, and M. Rafiei, Solidification Behavior and Laves Phase Dissolution During Homogenization Heat Treatment of Inconel 718 Superalloy, Vacuum, 2018, 154, p 235-243

18. G.L. Li, Y.L. Li, T.S. Dong et al., Microstructure and Interface Characteristics of NiCrBSi Thick Coating Remelted by TIG Process, Vacuum, 2018, 156, p 440-448

19. Y.L. Li, T.S. Dong, G.L. Li et al., Microstructure Evolution and Properties of NiCrBSi Thick Coating Remelted by Gas Tungsten Arc, Surf. Coat. Technol., 2018, 349, p 260-271

20. T. Liyanage, G. Fisher, and A.P. Gerlich, Influence of Alloy Chemistry on Microstructure and Properties in NiCrBSi Overlay Coatings Deposited by Plasma Transferred Arc Welding (PTAW), Surf. Coat. Technol., 2010, 205, p 759-765

21. X. Chen, X. Qin, Z. Zhu et al., Microstructural Evolution and Wear Properties of the Continual Local Induction Cladding NiCrBSi Coatings, J. Mater. Process. Technol., 2018, 262, p 257-268

22. L. Ren, M. Zhou, T. Lu et al., Eutectic Phase Strengthening and Strain Rate Sensitivity Behavior of AZ80 Magnesium Alloy, Mater. Sci. Eng., A, 2020, 770, p 138548

23. J. Li, S.L. Shrentha, Y. Long et al., The Formation of Eutectic Phases and Hot Cracks in One Ni-Mo-Cr Superalloy, Mater. Des., 2016, 93, p 324-333

24. D. Ye, C. Du, M. Wu et al., Microstructure and Mechanical Properties of Sn-xBi Solder Alloy, J. Mater. Sci.: Mater. Electron., 2015, 26, p 3629-3637

25. W. Yu and Q. Hao, The Phase Transformation of $\mathrm{Al}_{9}(\mathrm{Mn}, \mathrm{Ni})_{2}$ Eutectic Phase in an Al-4Ni-2Mn Alloy During Heat Treatment, Mater. Charact., 2017, 129, p 53-59

26. W. Yu, Q. Hao, and Q. Wang, Phase Transformation Behavior of $\mathrm{Al}_{9}(\mathrm{Mn}, \mathrm{Ni})_{2}$ Eutectic Phase During Heat Treatment at $600{ }^{\circ} \mathrm{C}$ in $\mathrm{Al}-$ 4Ni-2Mn Alloy, Trans. Nonferr. Met. Soc. China, 2018, 28, p 19131919

27. Y. Guo, M. Sun, B. Xu et al., A Method Based on Semi-solid Forming for Eliminating Laves Eutectic Phase of INCONEL 718 Alloy, J. Mater. Process. Technol., 2017, 249, p 202-211

28. V. Anggraini, A. Asadi, A. Syamsir et al., Three Point Bending Flexural Strength of Cement Treated Tropical Marine Soil Reinforced by Lime Treated Natural Fiber, Measurement, 2017, 111, p 158-166

29. S. Sun, H. Fu, X. Ping et al., Reinforcing Behavior and Microstructure Evolution of $\mathrm{NbC}$ in Laser Cladded Ni45 Coating, Appl. Surf. Sci., 2018,455 , p $160-170$ 
30. M. Liu, J. Takagi, and A. Tsukuda, Investigation of Strength Degradation and Strength Recovery via Short Time Heating for Ground Alumina Ceramics with Different Grain Size, J. Mater Process. Technol., 2004, 145, p 276-280

31. C. Du, Q. Pan, S. Chen et al., Effect of Rolling on the Microstructure and Mechanical Properties of 6061-T6 DS-FSW Plate, Mater. Sci. Eng., A, 2020, 772, p 138692

32. G.W. Hu, L.C. Zeng, H. Du et al., Tailoring Grain Growth and Solid Solution Strengthening of Single-Phase CrCoNi Medium-Entropy
Alloys by Solute Selection, J. Mater. Sci. Technol., 2020, 54, p 196205

Publisher's Note Springer Nature remains neutral with regard to jurisdictional claims in published maps and institutional affiliations. 